\title{
Serum and Circulatory Omentin mRNA Gene Expression as Predictive Markers of Systemic Lupus Erythematosus Disease Activity and Lupus Nephritis \\ Nearmeen M. Rashad ${ }^{* 1}$, Usama Khalil ${ }^{1}$, Mahmoud A. Sharafeddin ${ }^{1}$, Rehab M. Atef ${ }^{2}$, Marwa H.S. Hussien ${ }^{3}$, Magda M. Sherif ${ }^{1}$
}

Departments of ${ }^{1}$ Internal Medicine, ${ }^{2}$ Clinical Pathology and ${ }^{3}$ Medical Biochemistry \& Molecular Biology, Faculty of Medicine, Zagazig University, Zagazig, Egypt

*Corresponding author: Nearmeen M. Rashad, Mobile: (+20) 01224248642,

E-mail:nrashad78@yahoo.com; n.rashad@zu.edu.eg

\begin{abstract}
Background: Lupus nephritis (LN) affects $50 \%$ of systemic lupus erythematosus (SLE). LN often leads to renal failure. Thus, early diagnosis of LN is mandatory for the prevention of complications.

Objective: We aimed to evaluate serum and relative omentin mRNA gene expression levels as a noninvasive diagnostic test of LN and to assess their correlations with disease activity, clinical and laboratory features of SLE.

Patients and Methods: Case-control study included 104 subjects, 60 patients with SLE were stratified into two subgroups LN group $(n=25)$ and the non-LN group $(n=35)$. Disease activity was assessed by the SLE disease activity index (SLEDAI). Measurement of serum omentin was done by ELISA and investigation of omentin mRNA relative expression was done by real-time PCR.

Results: Our results detected that serum omentin levels were significantly lower in the LN group and non-LN group compared to controls. Intriguingly, omentin mRNA relative expression levels were significantly lower in the LN group and non-LN group compared to controls. Among the LN group, there were significant negative correlations between serum and relative omentin mRNA expression with SLEDAI, clinical, and laboratory features of LN. Moreover, SLEDAI, proteinuria, and serum creatinine were independently correlated with them. The sensitivities and the specificities of serum omentin were $91 \%$ and $65.5 \%$ respectively. While the relative omentin mRNA expression diagnostic power showed sensitivities and specificities of 93\% and $68.8 \%$ respectively.

Conclusion: LN group had significantly lower values of serum and relative omentin mRNA expression compared to non-LN and control groups. Additionally, it was negatively correlated with SLEDAI, clinical and laboratory features of LN. Thus, they could be used as non-invasive predictive markers of LN.
\end{abstract}

Keywords: SLE, Lupus nephritis, Omentin mRNA expression, SLEDAI, Real-time PCR.

\section{INTRODUCTION}

A preponderance of evidence confirmed that systemic lupus erythematosus (SLE) is an autoimmune disease that mainly affects females more than males, in particular females during the childbearing period. Intriguing reports are investigating the etiological factors of SLE and detected that the etiology is complex including genetic predisposition and immunological as well as hormonal influences ${ }^{(\mathbf{1})}$.

There is a lot of evidence that raised the issue that SLE may affect all the organs and tissues of the body such as the skin, joints, lungs, heart, and central nervous system, as well as the kidneys ${ }^{(2)}$.

A preponderance of evidence suggests that lupus nephritis (LN) is one of the most severe complications of SLE and is present in about $60 \%$ of patients ${ }^{(3)}$. It has been suggested that the pathological classification of $\mathrm{LN}$ focused on the degree of glomerular involvement. However, recent publications have addressed the value of vascular and tubulointerstitial changes, as well as the role of activity and chronicity indices in the prognosis of kidney outcomes ${ }^{(4)}$.
It has been postulated that autoantibodies, cytokines, and immune complex deposition are the main pathological causes of SLE. In addition, cytokines and autoantibodies levels were strongly related to renal diseases and can be used for the prediction of patients with $\mathrm{LN}{ }^{(3)}$. However, antibodies to dsDNA and the decrease of complements were also present in non-LN patients and clinically non-active SLE patients. It may be assumed that this lack of specificity of anti-dsDNA antibodies for renal activity was also detected in other biomarkers. Thus, there is a need to explore more specific and sensitive predictor biomarkers of $\mathrm{LN}$ and SLE severity ${ }^{(4)}$.

Omentin is a novel hydrophilic adipokine of 313 amino acids $(35 \mathrm{kDa})$. Mounting evidence indicates that omentin suppresses NFKB activity, TNF- $\alpha$, and CRP ${ }^{(5)}$.

Even more importantly, omentin genes encoding is proximal to the 1q22-q23 chromosomal region associated with type-2 diabetes mellitus (T2DM). Omentin-1 has an anti-inflammatory role in obesity and exerts its effects probably by inducing an 
increase in Th-2 cytokines comprising IL-13 and IL-4 (6).

There is growing evidence that the definitive diagnosis of LN can only be achieved by histological analysis of renal biopsies, but this method is invasive and has many limitations and complications. Thus, our study aimed to assess serum and mRNA relative expression level of omentin as a noninvasive predictive genetic marker of $\mathrm{LN}$ and to assess the correlations between serum and mRNA relative expression level of omentin with clinic-pathologic characteristics as well as disease activity of SLE.

\section{PATIENTS AND METHODS}

This is a case-control study that enrolled 60 patients with SLE who were recruited from Internal
Medicine Departments at the Zagazig University Hospitals and 44 control subjects who were age- and sex-matched with the patients. SLE patients were diagnosed according to 2012 Systemic Lupus International Collaborating Clinics (SLICC) classification criteria ${ }^{(7)}$.

All participants underwent a complete history taking and physical examination. Disease activity was measured using the SLE disease activity index (SLEDAI) ${ }^{(8)}$. Patients were divided into two groups non-lupus nephritis $(\mathrm{LN})$ group $(\mathrm{n}=35)$ and the $\mathrm{LN}$ group $(\mathrm{n}=25)$, the diagnosis of $\mathrm{LN}$ according to (SLICC) criteria. The diagnosis of renal involvement was confirmed by renal biopsy. The flowchart of the study is shown in (figure 1)

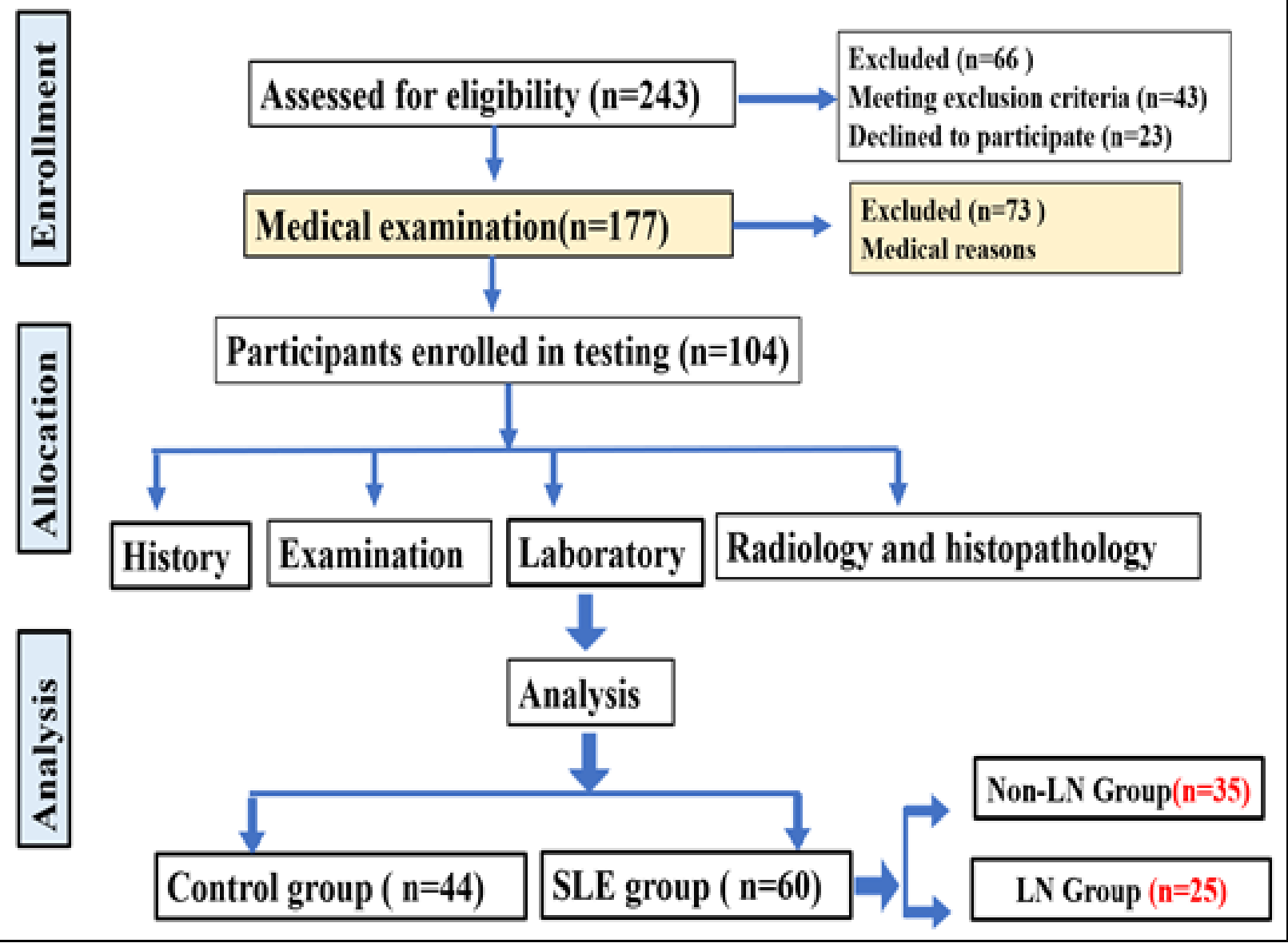

Figure (1): Flowchart of the study 
Exclusion criteria: We excluded patients with a history of myocardial infarction, angina, stroke, drug induced SLE, pregnancy, diabetes. In addition to the patients with hepatitis $C$ virus, hepatitis B virus, and other connective tissue diseases.

\section{Ethical approval:}

An approval of the study was obtained from Zagazig University Academic and Ethical Committee. Every patient signed an informed written consent for acceptance of the study. This work has been carried out in accordance with The Code of Ethics of the World Medical Association (Declaration of Helsinki) for studies involving humans.

\section{Blood sampling and analysis:}

Blood samples were drawn from all subjects after an overnight fasting. Sera were separated after $1 \mathrm{~h}$ longstanding and stored at $-80^{\circ} \mathrm{C}$. Serum urea and serum creatinine were determined using the spectrophotometric technique on Roche Cobas system (c501) autoanalyzer (Roche Diagnostics, Mannheim, Germany). Quantification of albumin levels in $24 \mathrm{~h}$ urine samples was performed by the immunoturbidimetric method using the same autoanalyzer. Twenty-four-hour urine samples were collected from each participant. The diagnosis of active urinary sediment was done as reviewed in Ortega et al. ${ }^{(9)}$. Renal biopsies were evaluated by an expert pathologist using the 2004 (ISN/RPS) classification ${ }^{(10)}$. We measured an Anti-doublestranded DNA antibody (anti-dsDNA), by the antidsDNA indirect immunofluorescence Kit NOVA Lite ${ }^{\circledR}$ dsDNA Crithidia Iuciliae kit (INOVA Diagnostics, Inc, San Diego, USA). The erythrocyte sedimentation rate (ESR) was determined manually, complement $\mathrm{C} 3$ and $\mathrm{C} 4$ were measured using immunoturbidimetric assay on Roche Cobas system (c501) autoanalyzer (Roche Diagnostics, Mannheim, Germany).

\section{Measurements of serum omentin-1:}

Serum omentin-1 concentrations were determined by Enzyme-Linked Immunosorbent Assay (ELISA) kit (CUSABIO Biotech Co., USA) according to the manufacturer's instructions using ELx808TM Absorbance Microplate Reader, Bio-Tek Instruments, USA.

\section{Omentin mRNA expression analysis:}

RNA extraction and quantitative real-time polymerase chain reaction (qRT-PCR):

RNA was extracted from peripheral blood samples of 60 patients and 45 controls using the NucleoSpin RNA Blood Kit (Macherey-Nagel, Germany), according to the manufacturer's instructions. Total RNA was reverse transcribed into complementary DNA (cDNA) using script Advanced cDNA Synthesis Kit for reverse transcriptionquantitative real-time PCR (qPCR) (Bio-Rad, USA), and cDNA was amplified with SsoAdvancedTM
Universal SYBR ${ }^{\circledR}$ Green Supermix (Bio-Rad, USA). qPCR reactions for omentin (target gene) and GAPDH (housekeeping gene) were performed in custom 384-well-plates (PrimePCR Assays, Bio-Rad, USA) in a 7900 HT real-time instrument (Applied Biosystems, USA). All samples were assayed in duplicate and experimental control assays were included. The primers were designed using Primer Premier 6.0 software (Premier, Canada), with the sequences as follows: omentin, forward 5'GACGCCCAGAAAACAG CATC-3', reverse 5'CGTTGGCTGCTCTCTCGTTA-3'. The relative omentin mRNA expression was analyzed by the comparative $\mathrm{Ct}$ method, as previously reported ${ }^{\left({ }^{(11)}\right.}$.

\section{Statistical analysis}

Data analysis was done using Statistical Package for the Social Sciences Software (SPSS Version 20, Chicago, Illinois). Findings were expressed as mean \pm standard deviation (SD), or number (percentage) when appropriate. Different parameters in the two studied groups were compared using an unpaired t-test. The associations of serum and mRNA relative expression level of omentin with clinical and laboratory parameters among the LN group were tested with Pearson correlation coefficient. Further evaluation of independent factors correlated with serum and mRNA relative expression level of omentin was investigated with linear regression analysis. Receiver operating characteristic (ROC) analysis was performed to assess the potential diagnostic accuracy of serum and mRNA relative expression level of omentin levels, the area under the curve (AUC), and the cutoff values. We considered $\mathrm{P}$ to be significant at $\leq 0.05$ with a $95 \%$ confidence interval (CI).

\section{RESULTS}

\section{Clinical and laboratory characteristics of SLE groups:}

Among patients with SLE ( $\mathrm{n}=60$ ), in the $\mathrm{LN}$ group $(\mathrm{n}=25), 92 \%$ were females and $8 \%$ were males, their mean age was $33.2 \pm 6.12$ years and the mean disease duration was $3.86 \pm 1.82$ years. In the non-LN group $(\mathrm{n}=35), 91.4 \%$ were females and $8.6 \%$ were males, their mean age was $31.97 \pm 7.67$ years and the mean disease duration was $4.24 \pm 1.33$ years. Both groups of patients were matched for age, gender, and disease duration. There were significantly higher values of SLEDAI in the LN group compared to the non-LN group. Regarding clinical findings, there was a significantly higher prevalence of hypertension in the LN group compared to the non-LN group. As expected, there were significantly higher values of proteinuria, pus cell, cellular casts, hematuria, serum creatinine, serum urea, anemia, thrombocytopenia, CRP, and ESR in the LN group compared to the nonLN group. On the other hand, there were significantly lower values of eGFR, $\mathrm{C} 3$, and $\mathrm{C} 4$ in the $\mathrm{LN}$ group compared to the non- LN group, $\mathrm{P}<0.001^{*}$ (Table 1). 
Table (1): Clinical and laboratory characteristics of SLE groups

\begin{tabular}{|l|c|c|c|}
\hline \multirow{2}{*}{ Variables } & \multicolumn{2}{|c|}{ SLE (n=60) } & \multirow{2}{*}{ P value } \\
\cline { 2 - 3 } & $\begin{array}{c}\text { LN group } \\
(\mathbf{n = 2 5})\end{array}$ & $\begin{array}{c}\text { Non-LN group, } \\
(\mathbf{n = 3 5})\end{array}$ & \\
\hline Age (years) & $31.97 \pm 7.67$ & $33.25 \pm 6.12$ & 0.828 \\
\hline Male/female, number & $3 / 32$ & $2 / 23$ & 0.541 \\
\hline Duration of disease (years) & $4.24 \pm 1.33$ & $3.86 \pm 1.82$ & 0.732 \\
\hline SLEDAI & $9.04 \pm 2.75$ & $17.6 \pm 8.57$ & $<0.001^{*}$ \\
\hline Fever (n, \%) & $11(31.4 \%)$ & $19(76 \%)$ & 0.087 \\
\hline Hypertension & $3(8.5 \%)$ & $21(84 \%)$ & $<0.001^{*}$ \\
\hline Proteinuria & $0(0 \%)$ & $18(72 \%)$ & $<0.001^{*}$ \\
\hline Pus cell & $3(8.5 \%)$ & $18(72 \%)$ & $<0.001^{*}$ \\
\hline Cellular casts & $0(0 \%)$ & $20(80 \%)$ & $<0.001^{*}$ \\
\hline Hematuria & $0(0 \%)$ & $19(76 \%)$ & $<0.001^{*}$ \\
\hline Serum creatinine $(\mathrm{mg} / \mathrm{dL})$ & $0.83 \pm 0.23$ & $2.74 \pm 1.41$ & $<0.001^{*}$ \\
\hline Serum urea $(\mathrm{mg} / \mathrm{dL})$ & $35.06 \pm 17.3$ & $59.06 \pm 33.2$ & $<0.001^{*}$ \\
\hline eGFR $\left(\mathrm{ml} / \mathrm{min} / 1.73 \mathrm{~m}^{2}\right)$ & $89.7 \pm 11.4$ & $54.47 \pm 21.5$ & $<0.001^{*}$ \\
\hline Anemia & $11(31.4 \%)$ & $20(80 \%)$ & $<0.001^{*}$ \\
\hline Thrombocytopenia $(<100.000 / \mathrm{mm})$ & $5(14.2 \%)$ & $17(68 \%)$ & $<0.001^{*}$ \\
\hline Lymphopenia $(<1500 / \mathrm{mm})$ & $4(11.4 \%)$ & $11(44 \%)$ & $<0.001^{*}$ \\
\hline Leucopenia $(<4000 / \mathrm{mm})$ & $4(11.4 \%)$ & $11(44 \%)$ & $<0.001^{*}$ \\
\hline CRP $(\mathrm{mg} / \mathrm{dL})$ & $6.69 \pm 1.5$ & $23.92 \pm 9.3$ & $<0.001^{*}$ \\
\hline ESR $(\mathrm{mm} / \mathrm{h})$ & $36.7 \pm 10.3$ & $84.8 \pm 34.9$ & $<0.001^{*}$ \\
\hline C3 $(\mathrm{mg} / \mathrm{dL})$ & $65.47 \pm 7.2$ & $35.87 \pm 5.5$ & $<0.001^{*}$ \\
\hline C4 $(\mathrm{mg} / \mathrm{dL})$ & $33.47 \pm 11.1$ & $16.87 \pm 6.6$ & $<0.001^{*}$ \\
\hline
\end{tabular}

LN; lupus nephritis, SLEDAI; systemic lupus erythematosus disease activity index, e GFR; estimated glomerular filtration, ESR; erythrocyte sedimentation rate, CRP; C-reactive protein, C3; complement 3, C4; complement 4. ${ }^{*} \mathrm{P}<0.05$.

\section{Comparison of serum and mRNA relative expression levels of omentin:}

Serum omentin levels were significantly lower in the LN group and non-LN group compared to controls $(310.1 \pm 100.083 \& 350.9 \pm 90.956$ vs. $430.6 \pm 90.55 \mathrm{ng} / \mathrm{mL}$, respectively, p < 0.001) (Fig. 2a). Interestingly, omentin mRNA relative expression levels were significantly lower in the LN group and non-LN group compared to controls ( $2.45 \pm 1.18 \& 3.35 \pm 0.93$ vs. $4.34 \pm 0.94$, respectively, p < 0.001) (Fig. 2b).

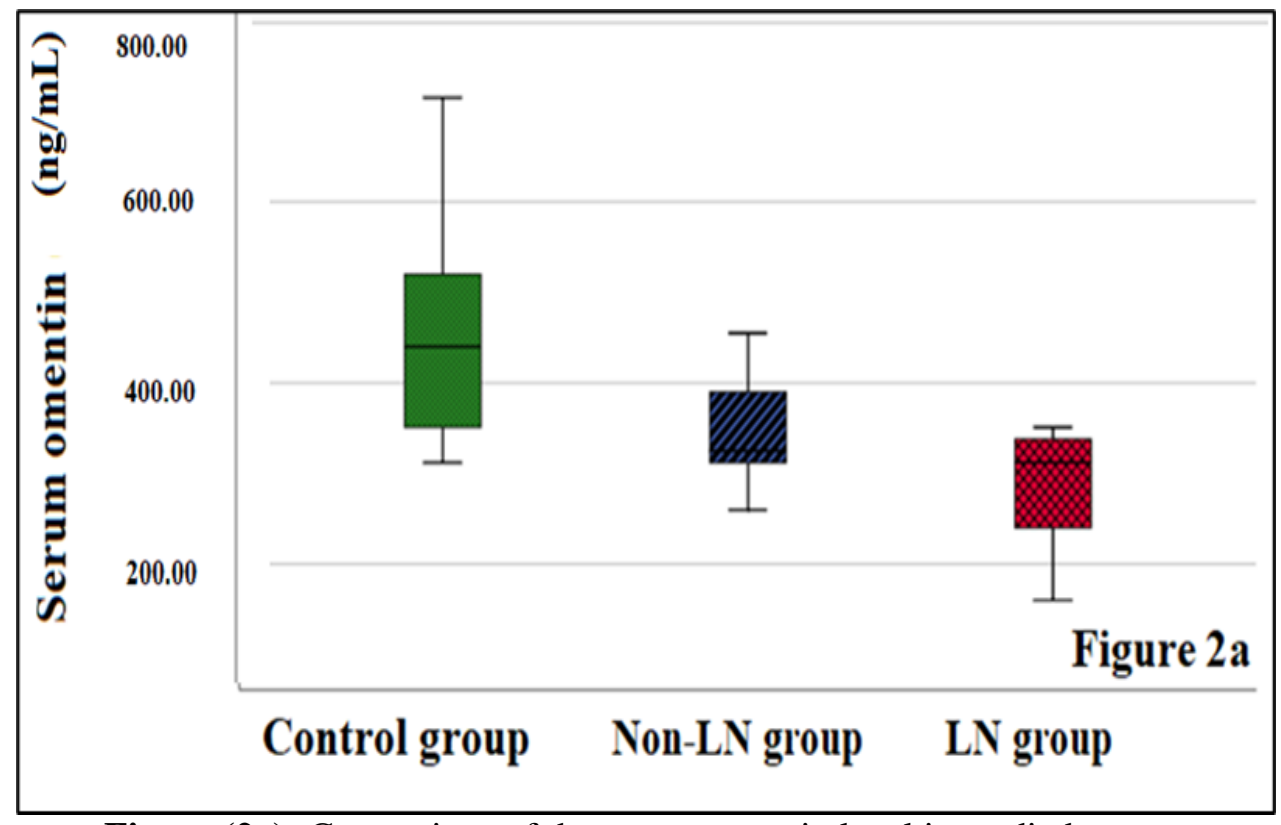

Figure (2a): Comparison of the serum omentin level in studied groups 


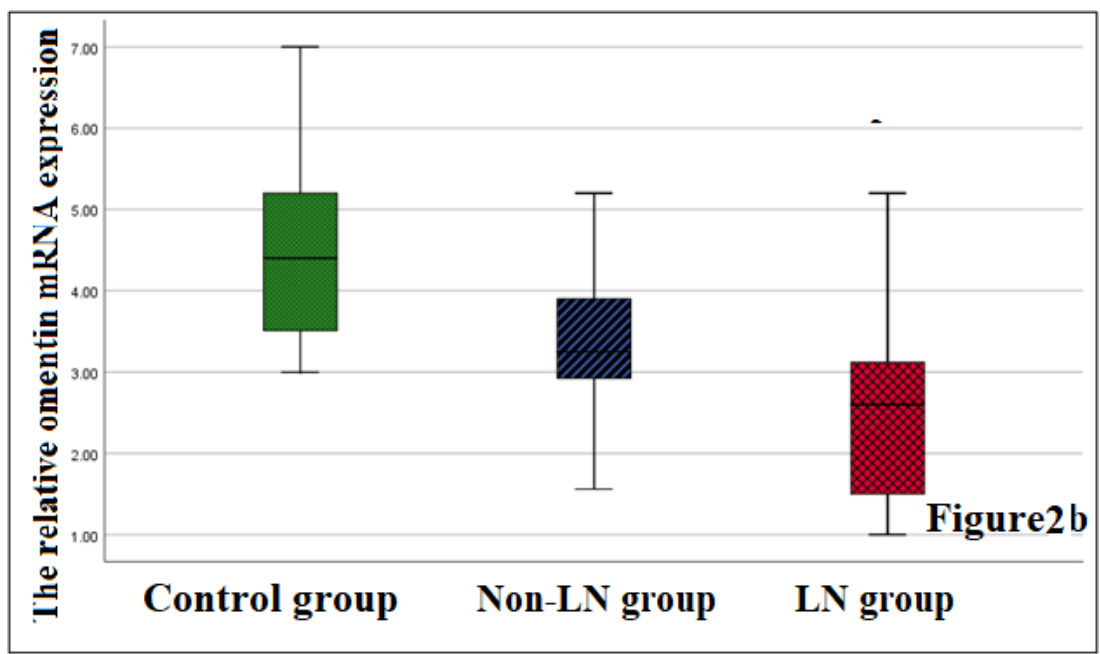

Figure (2b): Comparison of the relative omentin expression level in studied groups

Pearson correlation between serum omentin $(\mathrm{ng} / \mathrm{ml})$, relative omentin mRNA expression, and clinicpathologic characteristics of $L N$ :

There were significant negative correlations between serum omentin $(\mathrm{ng} / \mathrm{ml})$ and SLEDAI as well as proteinuria, pus cell, cellular casts, hematuria, serum creatinine, thrombocytopenia, lymphopenia, and ESR. On the contrary, serum omentin levels were positively correlated with eGFR, C3, and C4 P $<0.001 *$. Regards the relative omentin mRNA expression correlations, there were significant negative correlations with SLEDAI, proteinuria, pus cell, cellular casts, hematuria, serum creatinine, thrombocytopenia, lymphopenia, and ESR. On the contrary, the relative omentin mRNA expression levels were positively correlated with eGFR, C3, and C4 P < $0.001 *$ (Table 2).

Table (2): Pearson correlation between serum omentin ( $\mathrm{ng} / \mathrm{ml})$, relative omentin mRNA expression and clinicpathologic characteristics of LN

\begin{tabular}{|l|c|c|c|c|}
\hline \multirow{2}{*}{ Variables } & \multicolumn{2}{c|}{ Serum omentin $(\mathbf{n g} / \mathbf{m l})$} & \multicolumn{2}{c|}{ Omentin mRNA level } \\
\cline { 2 - 5 } & $\boldsymbol{R}$ & $\mathrm{P}$ value & $\boldsymbol{r}$ & $\mathrm{P}$ value \\
\hline SLEDAI & -0.241 & $<0.001^{*}$ & -0.331 & $<0.001^{*}$ \\
\hline Hypertension & -0.142 & 0.045 & -0.163 & 0.017 \\
\hline Proteinuria & -0.352 & $<0.001^{*}$ & -0.411 & $<0.001^{*}$ \\
\hline Pus cell & -0.424 & $<0.001^{*}$ & -0.394 & $<0.001^{*}$ \\
\hline Cellular casts & -0.550 & $<0.01^{*}$ & -0.360 & $<0.01^{*}$ \\
\hline Hematuria & -0.349 & $<0.001^{*}$ & -0.394 & $<0.001^{*}$ \\
\hline Serum creatinine (mg/dL) & -0.197 & $<0.001^{*}$ & -0.394 & $<0.001^{*}$ \\
\hline eGFR (ml/min/1.73m $\mathbf{2})$ & 0.462 & $<0.001^{*}$ & 0.621 & $<0.001^{*}$ \\
\hline Anemia & -0.022 & 0.686 & -0.089 & 0.245 \\
\hline Thrombocytopenia & -0.320 & $<0.001^{*}$ & -0.193 & -0.189 \\
\hline Lymphopenia & -0.940 & $<0.01^{*}$ & -0.565 & 0.084 \\
\hline Leucopenia & -0.103 & 0.134 & -0.128 & 0.220 \\
\hline CRP (mg/dL) & -0.155 & 0.029 & -0.071 & -0.260 \\
\hline ESR (mm/h) & -0.209 & $<0.001^{*}$ & -0.223 & $<0.001^{*}$ \\
\hline C3 (mg/dl) & 0.660 & $<0.001^{*}$ & 0.450 & $<0.001^{*}$ \\
\hline C4 (mg/dl) & 0.232 & $<0.001$ & 0.270 & $<0.001$ \\
\hline
\end{tabular}

e GFR; estimated glomerular filtration, ESR; erythrocyte sedimentation rate, CRP; C-reactive protein; C3; complement 3, C4; complement 4. *P<0.05.

Linear regression analyses to test the influence of the main independent variables against serum omentin $(\mathrm{ng} / \mathrm{ml})$ and relative omentin mRNA expression levels (dependent variable) in LN group:

Linear regression analysis test was done to evaluate the main effectors of serum omentin and the relative omentin mRNA expression levels among LN group. The interesting findings of the current study showed that SLEDAI, proteinuria, and serum creatinine were independently correlated with both studied markers among LN patients $\mathrm{P}<0.001 *$ (Table 3 ). 
Table (3): Linear regression analyses to test the influence of the main independent variables against serum omentin (ng/ml) and relative omentin mRNA expression levels (dependent variable) in lupus nephritis group

\begin{tabular}{|c|c|c|c|c|c|c|c|c|}
\hline \multicolumn{3}{|c|}{$\begin{array}{l}\text { Unstandardized } \\
\text { Coefficients }\end{array}$} & \multicolumn{2}{|c|}{$\begin{array}{c}\text { Standardized } \\
\text { Coefficients }\end{array}$} & \multirow{2}{*}{$\mathbf{t}$} & \multirow{2}{*}{$\mathbf{p}$} & \multicolumn{2}{|c|}{ 95\% C.I. } \\
\hline Model & B & SE & \multicolumn{2}{|c|}{ Beta } & & & $\begin{array}{l}\text { Lower } \\
\text { Bound }\end{array}$ & $\begin{array}{l}\text { Upper } \\
\text { Bound }\end{array}$ \\
\hline \multirow[t]{5}{*}{$\begin{array}{l}\text { Serum } \\
\text { omentin }\end{array}$} & (Constant) & -148.297 & 12.46 & & -11.89 & $<0.001^{*}$ & $\begin{array}{c}- \\
173.046 \\
\end{array}$ & 123.549 \\
\hline & SLEDAI & 29.448 & 0.945 & 0.883 & 31.14 & $<0.001^{*}$ & 27.571 & 31.325 \\
\hline & Proteinuria & 2.939 & 0.418 & 0.241 & 7.038 & $<0.001^{*}$ & 2.110 & 3.768 \\
\hline & Creatinine & 1.073 & 0.281 & 0.522 & 3.811 & $<0.001^{*}$ & 0.514 & 1.631 \\
\hline & ESR & 0.105 & 0.195 & 0.058 & 0.537 & 0.593 & -0.283 & 0.493 \\
\hline \multirow{5}{*}{$\begin{array}{l}\text { Relative } \\
\text { expression of } \\
\text { Omentin }\end{array}$} & (Constant) & 89.153 & 4.775 & & 18.669 & $<0.001^{*}$ & 79.671 & 98.635 \\
\hline & SLEDAI & -2.703 & 0.769 & -0.848 & -3.517 & $<0.001^{*}$ & -4.229 & -1.177 \\
\hline & Proteinuria & -1.014 & 0.125 & -0.869 & -8.109 & $<0.001$ & -1.262 & -0.766 \\
\hline & Creatinine & -0.061 & .015 & -0.518 & -4.000 & $<0.001^{*}$ & -0.091 & -0.031 \\
\hline & ESR & -0.040 & 0.192 & -0.023 & -0.207 & 0.836 & -0.421 & 0.341 \\
\hline
\end{tabular}

SLEDAI; systemic lupus erythematosus disease activity index; ESR; erythrocyte sedimentation rate; 95\% C.I.; $95 \%$ confidence interval. * Significant $\mathrm{P}$ value $(\mathrm{P}<0.05)$

Accuracy of serum omentin (ng/ml), relative omentin mRNA expression levels for discriminating $\mathrm{LN}$ among SLE patients by ROC analysis.

The potential diagnostic value of serum omentin $(\mathrm{ng} / \mathrm{ml})$ is shown in figure (3a), the cutoff value of serum omentin was 320.75 and the AUC was 0.763 (95\% CI =0.667-0.859). Additionally, the sensitivities and the specificities of serum omentin were $91 \%$ and $65.5 \%$ respectively. As regards the relative omentin mRNA expression diagnostic power as shown in figure (3b), the cutoff value was 2.72 and the AUC was $0.808(95 \% \mathrm{CI}=$ 0.723-0.894). Additionally, the sensitivities and the specificities of relative omentin mRNA expression were $93 \%$ and $68.8 \%$ respectively.

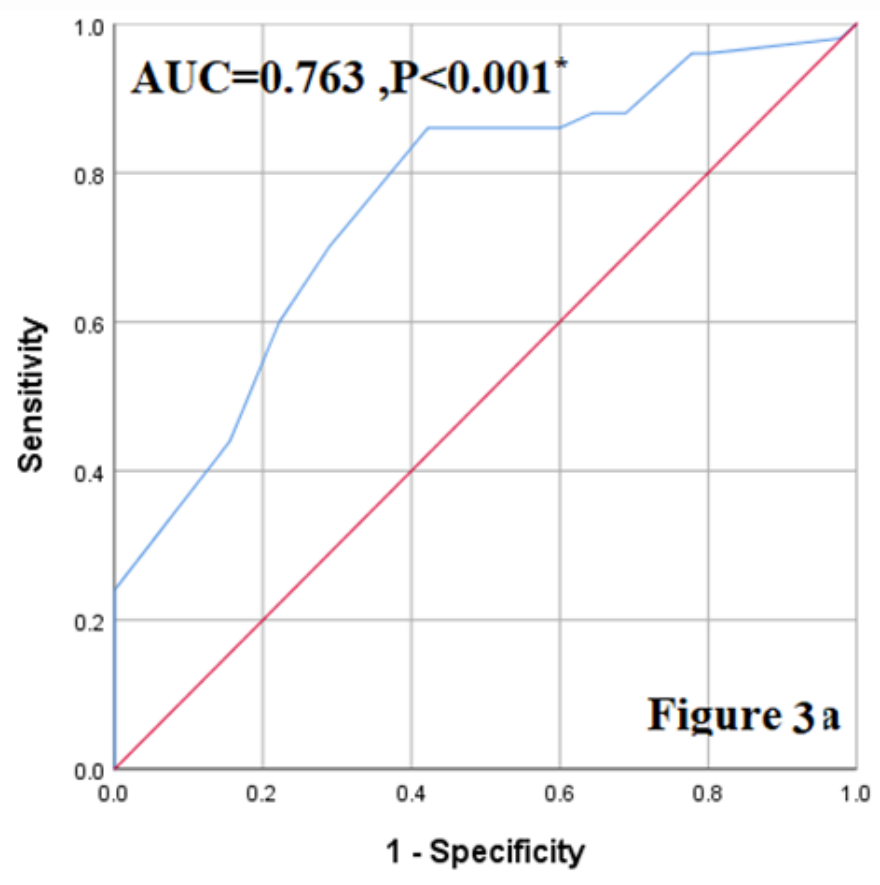

Figure (3a): Receiver operating characteristic (ROC) curve for serum omentin level for differentiation between LN group from non-LN group. 


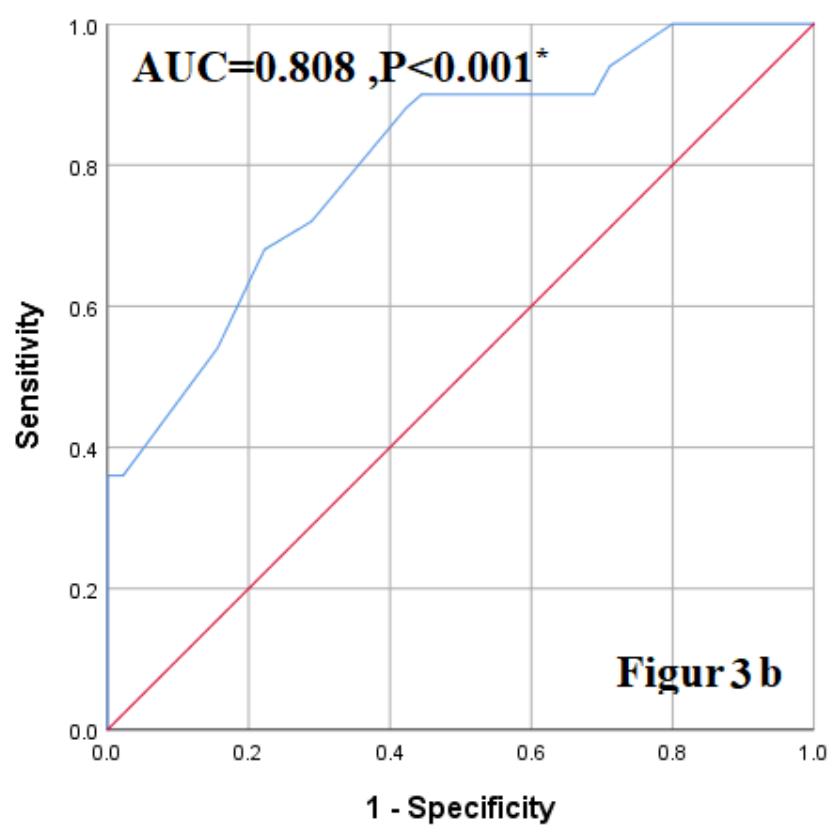

Figure (3b): Receiver operating characteristic (ROC) curve for relative omentin expression level for differentiation between $\mathrm{LN}$ group from non-LN group.

\section{DISCUSSION}

A growing body of evidence has corroborated that SLE is a multi-system autoimmune chronic disease of an unidentified cause. Renal involvement is a common characteristic of SLE and frequently occurs in the first years of disease ${ }^{(12)}$. More than $50 \%$ of patients with SLE will develop $\mathrm{LN}$, and about $20 \%$ of $\mathrm{LN}$ patients will have progression to end-stage renal disease (ESRD) ${ }^{(13,14)}$. A growing body of evidence has corroborated that LN can involve the glomeruli, interstitium, tubules, and vessels with immune complex deposition in all four compartments. Recently, among the various mechanisms triggering the pathogenesis of $\mathrm{LN}$, adipokines have emerged as important regulators of this deleterious process ${ }^{(\mathbf{1 5})}$. Omentin is an adipokine that has anti-inflammatory actions. Omentin exerts its inhibitory effects through modulation of TNFalfa phosphorylation, Janus kinase pathway activation, and NF-kB pathway through suppression of nuclear accumulation of $\mathrm{p} 65$, NF-kB promoter activity, and attenuation of LPS-induced inflammation in macrophages ${ }^{(16)}$. Our study aimed to assess serum and mRNA relative expression level of omentin as a noninvasive predictive genetic marker of $\mathrm{LN}$ and to assess their correlations with clinic-pathologic characteristics as well as disease activity of SLE.

In the current study, we observed nonsignificant differences between studied groups as regards age, sex, and disease duration. In the $\mathrm{LN}$ group, about $92 \%$ of patients were females and $8 \%$ were males, their mean age was $33.2 \pm 6.12$ years, and the mean disease duration was $3.86 \pm 1.82$ years. In the non-LN group, $91.4 \%$ were females and $8.6 \%$ were males, their mean age was $31.97 \pm 7.67$ years and the mean disease duration was $4.24 \pm 1.33$ years. Similar results were observed in our previous research as we detected non-significant differences between studied groups regarding age, gender and disease duration ${ }^{(\mathbf{1 7})}$.

The results of our research demonstrate that there were significantly higher values of SLEDAI, hypertension, proteinuria, pus cell, cellular casts, hematuria, serum creatinine, serum urea, anemia, thrombocytopenia, CRP, and ESR in the LN group compared to the non-LN group. On the contrary, there were significantly lower values of eGFR, C3, and $\mathrm{C} 4$ in the $\mathrm{LN}$ group compared to the non- $\mathrm{LN}$ group. The same findings were found in our previous study as there were significantly higher values of SLEDAI, vasculitis, and hypertension in the $\mathrm{LN}$ group compared to the non-LN group ${ }^{\left({ }^{(17)}\right.}$. In the study conducted by Abdallah et al. the LN group had higher values of hypertension, proteinuria, pus cell, cellular casts, hematuria, serum creatinine, serum urea, eGFR, thrombocytopenia, and ESR compared to the non-LN group ${ }^{(18)}$.

The interesting result of our study was that serum and mRNA relative expression levels of omentin were significantly lower in the LN group compared to other studied groups. Interestingly, in the LN group, there were significant negative correlations between serum and relative omentin mRNA expression with SLEDAI, proteinuria, pus cell, cellular casts, hematuria, serum creatinine, thrombocytopenia, lymphopenia, and ESR. On the contrary, serum omentin levels were positively correlated with eGFR, C3, and C4.

An interesting study by Zhang et al. (19) investigated the possible association between omentin-1 genetic polymorphisms with SLE in a Chinese population. They observed that in omentin1, the rs13376023 A allele was found to be related to oral ulcers in SLE patients, and the rs35779394 C and rs13376023 A allele frequencies were significantly lower in SLE patients.

Recently, published studies highlighted the role of omentin in the regulation of innate immune response to parasite infection ${ }^{(20)}$, even more importantly numerous studies have shown that omentin gene expression is altered in obesity ${ }^{(21)}$. Additionally, Kuperman et al. (22) have found altered gene expression of omentin in patients with asthma and omental adipose tissue of patients with Crohn's disease, suggesting that omentin could be a novel inflammatory marker implicated in chronic inflammatory diseases ${ }^{(5)}$.

We further evaluated our results by linear regression analysis test that was done to evaluate the main effectors of serum omentin and the relative omentin mRNA expression levels among the LN group. We found that SLEDAI, proteinuria, and 
serum creatinine were independently correlated with serum and relative omentin mRNA expression among LN patients by ROC curve. We analysed the potential diagnostic value of serum and relative omentin mRNA expression for discriminating LN among SLE patients and we detected that the sensitivities and the specificities of serum omentin were $91 \%$ and $65.5 \%$ respectively. While the relative omentin mRNA expression diagnostic power showed sensitivities and specificities of $93 \%$ and $68.8 \%$ respectively.

\section{CONCLUSION}

The LN group had significantly lower values of serum and relative omentin mRNA expression compared to non-LN and control groups. Besides they were negatively correlated with SLEDAI, clinical and laboratory features of LN. Thus, they could be used as non-invasive predictive markers of LN.

\section{Financial support and sponsorship: Nil.}

Conflict of interest: Nil.

\section{REFERENCES}

1. Anaya J, Shoenfeld Y, Rojas-Villarraga A et al. (2013): Autoimmunity: From Bench to Bedside. Bogota (Colombia): El Rosario University Press;https://pubmed.ncbi.nlm.nih.Gov /29087650/

2. Schwartz N, Goilav B, Puttermanc C (2014): The pathogenesis, diagnosis and treatment of lupus nephritis. Curr Opin Rheumatol., 26: 502-509.

3. Hogan J, Appel G (2013): Update on the treatment of lupus nephritis. Curr Opin Nephrol Hypertens., 22: 224-230.

4. Bajema I, Wilhelmus S, Alpers C et al. (2018): Revision of the International Society of Nephrology/Renal Pathology Society classification for lupus nephritis: clarification of definitions, and modified National Institutes of Health activity and chronicity indices. Kidney Int., 93 (4): 789-96.

5. Yang R, Lee M, Hu H et al. (2006): Identification of omentin as a novel depot-specific adipokine in human adipose tissue: Possible role in modulating insulin action. Am J Physiol Endocrinol Metab., 290: 12531261.

6. Schaffler A, Neumeier M, Herfarth $H$ et al. (2005): Genomic structure of human omentin, a new adipocytokine expressed in omental adipose tissue. Biochim Biophys Acta., 1732: 96-102.

7. Petri M, Orbai A, Alarcón G et al. (2012): Derivation and validation of the systemic lupus international collaborating clinics classification criteria for systemic lupus erythematosus. Arthritis Rheum., 64 (8): 267786.
8. Bombardier C, Gladman D, Urowitz M et al. (1992): Derivation of the SLEDAI. A disease activity index for lupus patients. The committee on prognosis studies in SLE. Arthritis Rheum., 35: 630-40

9. Ortega L, Schultz D, Lenz O et al. (2010): Lupus nephritis: pathologic features, epidemiology and a guide to therapeutic decisions. Lupus, 19 (5): 557-574.

10. Moroni G, Quaglini S, Maccario M et al. (1996): "Nephritic flares" are predictors of bad long-term renal outcome in lupus nephritis. Kidney Int., 50:2047-2053.

11. de Souza Batista $C$, Yang $R$, Lee $M$ et al. (2007): Omentin plasma levels and gene expression are decreased in obesity. Diabetes, 56: 1655-61.

12. Liang C, Huang C, Wang I et al. (2010): Impact of renal survival on the course and outcome of systemic lupus erythematosus patients treated with chronic peritoneal dialysis. Ther Apher Dial., 14: 35-42.

13. Wallace D, Podell T, Weiner J et al. (1982): Lupus nephritis: experience with 230 patients in a private practice from 1950 to 1980. Am J Med., 72 (2): 20920.

14. Mojcik C, Kuppel J (1996): End-stage renal disease and systemic lupus erythematosus. Am J Med., 101 (1): $100-7$.

15. Weening J, D'Agati V, Schwartz M et al. (2004): The classification of glomerulonephritis in systemic lupus erythematosus revisited. J Am Soc Nephrol., 15 (2): 241-50.

16. Kazama K, Usui T, Okada M et al. (2012): Omentin plays an anti-inflammatory role through inhibition of TNF- $\alpha$-induced superoxide production in vascular smooth muscle cells. European Journal of Pharmacology, 686 (1-3): 116-123.

17. Abdul-Maksoud $\mathrm{R}$, Rashad $\mathrm{N}$, Elsayed $\mathrm{W}$ et al. (2021): Circulating miR-181a and miR-223 expression with the potential value of biomarkers for the diagnosis of systemic lupus erythematosus and predicting lupus nephritis. J Gene Med., 23: 3326.

18. Abdallah E, Waked E, Abdelwahab M (2016): Evaluating the association of interleukin-10 gene promoter- 592 A/C polymorphism with lupus nephritis susceptibility. Kidney Res Clin Pract., 35: 29-34.

19. Zhang T, Li H, Li R et al. (2020): Association of omentin-1, adiponectin, and resistin genetic polymorphisms with systemic lupus erythematosus in a Chinese population. International Immunopharmacology, 83: 106343.

20. Gerwick L, Corley-Smith G, Bayne C (2007): Gene transcript changes in individual rainbow trout livers following an inflammatory stimulus. Fish and Shellfish Immunology, 22 (3): 157-171.

21. de Souza Batista C, Yang R, Lee M et al. (2007): Omentin plasma levels and gene expression are decreased in obesity. Diabetes, 56(6): 1655-1661.

22. Kuperman D, Lewis C, Woodruff $P$ et al. (2005): Dissecting asthma using focused transgenic modeling and functional genomics. Journal of Allergy and Clinical Immunology, 116 (2): 305-311. 